derives a population of Tregs that is stable and functionally superior compared to freshly isolated Tregs.

Disclosure of Interest

None Declared.

\section{PTU-123 USE OF RITUXIMAB IN RESISTANT AUTOIMMUNE HEPATITIS - BIRMINGHAM EXPERIENCE}

${ }^{1,2} \mathrm{~N}$ Gautam*, ${ }^{1,3} \mathrm{NN}$ Than, ${ }^{1,4} \mathrm{M}$ Nizamuddin, 1,3 D Adams, ${ }^{1,3} \mathrm{YH}$ Oo. ${ }^{1}$ Queen Elizabeth Hospital, Birmingham, UK; ${ }^{2}$ Gastroenterology, Walsall Healthcare NHS Trust, Walsall; ${ }^{3}$ Centre for Liver Research and NIHR BRU, University of Birmingham, UK; ${ }^{4}$ Gastroenterology, Russels Hall Hospital, Birmingham, UK

10.1136/gutinl-2014-307263.197

Introduction Autoimmune hepatitis (AIH) is due to breakdown in immunological self-tolerance. Sustained remission in AIH is crucial to prevent the progression to end stage liver disease. ${ }^{1}$ Around $9 \%$ of the patients are refractory/intolerant to the standard therapy with prednisolone (Pred) \pm azathioprine (AZA). High levels of immunoglobulin are typical of AIH and plasma cells are frequently observed in liver histology. Rituximab is an anti-CD20 monoclonal antibody that depletes B-cells and has been used to treat other autoimmune conditions such as systemic lupus erythematosus. However, little has been reported on the role of B cells depletion and its outcome in AIH.

The aim of the study was to evaluate the safety and efficacy of rituximab in the treatment of refractory $\mathrm{AIH}$.

Methods A retrospective case note review of well-defined and biopsy proven type-1 AIH (simplified scoring >6). 5 patients out of 200 who were intolerant/refractory to standard therapy were given Rituximab and the responses were followed up for 72 weeks.

Efficacy was measured by biochemical and immunological parameters (bilirubin, AST, ALT and Immunoglobulin every 12 weeks. The dose of Prednisolone as well as UKELD/MELD score pre and post treatment was also evaluated.

Results All 5 patients were female and mean age was 45 (range $35-66$ yrs). The rituximab dose used was $1000 \mathrm{mg}$ and the total number of doses received varied between 2 and 4 (Mean 3.2). Three patients had other concomitant autoimmune conditions (endocrine, rheumatological and renal related autoimmune diseases). The mean dose of prednisolone used pre-rituximab was $19 \mathrm{mg}( \pm$ SD 12.57$)$ and this was reduced to $12.5 \mathrm{mg}$ ( \pm SD 5.0) post treatment (statistically not significant $=$ NS). There was a slight improvement of IgG pre and post Rituximab treatment (NS), with no improvement in UKELD score. There was an improvement in biochemical profile but this was not statistically significant throughout the observation period. All five patients were alive and rituximab was well tolerated without any serious adverse events.

Conclusion Rituximab is well-tolerated and safe to use in resistant AIH. It can cause some biochemical and immunological improvement. Current evidence for its use in AIH patients is not well proven. The study numbers are too small to detect the actual outcome of the therapy. A multicenter larger cohort prospective study with longitudinal immunological, biochemical and histological profile assessment is warranted to assess its efficacy in resistant $\mathrm{AIH}$ patients.

\section{REFERENCE}

1 Czaja AJ. Current and future treatments of AlH. Expert Rev Gastroenterology Hepatol 2009:3: 269-91

Disclosure of Interest None Declared.

\section{PTU-124 AN EXTERNAL VALIDATION OF THE HEPATOMA ARTERIAL-EMBOLISATION PROGNOSIS (HAP) SCORE: THE LIVERPOOL EXPERIENCE}

${ }^{1} O$ Noorullah*, ${ }^{2} V P$ Lekharaju, ${ }^{3} \mathrm{UU}$ Din, ${ }^{3} \mathrm{~J}$ Klcova, ${ }^{4} \mathrm{~T}$ Cross, ${ }^{5} \mathrm{~J}$ Evans, ${ }^{1} \mathrm{R}$ Sturgess, ${ }^{6} \mathrm{D}$ Palmer, ${ }^{3} \mathrm{E} \mathrm{O}^{\prime} \mathrm{Grady},{ }^{1} \mathrm{~N}$ Stern. ${ }^{1}$ Digestive Diseases Unit, Liverpool, UK; ${ }^{2}$ Aintree University Hospital, Liverpool, UK; ${ }^{3}$ Department of Radiology, Aintree University Hospital, UK; ${ }^{4}$ Department of Gastroenterology, Royal Liverpool University Hospital; ${ }^{5}$ Department of Radiology, Royal Liverpool University Hospital; ${ }^{6}$ University of Liverpool, Liverpool, UK

\subsection{6/gutjnl-2014-307263.198}

Introduction Most Hepatocellular Carcinomas (HCCs) have palliative treatment. Trans-arterial embolisation (TAE) or chemoembolisation (TACE) are used with variable results. The HAP score was recently described to determine patients likely to benefit from TAE or TACE. We report our experience with TAE and TACE to assess whether the HAP score was valid for our cohort of patients.

Methods Retrospective review of cases given TAE or TACE in Liverpool, UK (2006-2013). HAP score [1 point each for albu$\min <36 \mathrm{~g} / \mathrm{dl}$, AFP $>400 \mathrm{ng} / \mathrm{ml}$, Bilirubin $>17 \mu \mathrm{mol} / \mathrm{l}$, tumour diameter $>7 \mathrm{~cm}$. HAP A $=0$ points, $\mathrm{B}=1, \mathrm{C}=2, \mathrm{D}$ $>2]$. Outcome recorded according to HAP score.

Results 137 patients identified having received TAE/TACE with full data to complete HAP score. Mean age 69; 116 (84.7\%) male. 78.8\% AUH, 21.2\% RLUH. HAP score A: 44 (32.1\%); B: 40 (29.2\%); C: 32 (23.4\%); D: 21 (15.3\%). Overall median survival 492 days (16 months). Median survival by HAP score, A: 492 days; B: 839 days; C 478 days; D 309 days. Log rank p < 0.001. Survival at 1 year: A $62.8 \%$; B 75\%; C59.4\%, D 28.6\%. Survival at 2 years: A $29.5 \%$, B $52.5 \%$, C $37.5 \%$, D $14.3 \%$. HAP D patients had lower median survival (309 vs. 563 days; $p$ $<0.001$ ) and 1 and 2 year survival (28.6 vs. $65.5 \%$; $\mathrm{p}=0.001$ and 14.3 vs $39.7 \% ; \mathrm{p}=0.021$ ).

Conclusion Patients with HAP score D due TACE have a relatively poor outcome in this external validation group. This should be considered when planning treatment or further trials.

\section{REFERENCE}

Kadalayil et al. Annals of Oncology 2013

Disclosure of Interest None Declared.

\section{PTU-125 BIOCHEMICAL PATTERNS OF PRESENTATION IN PRIMARY SCLEROSING CHOLANGITIS: YOUNGER AGE AT ONSET IS ASSOCIATED WITH A LOWER ALPIAST RATIO}

${ }^{1}$ PJ Trivedi ${ }^{*},{ }^{1} J$ Robinson, ${ }^{1} \mathrm{~T}$ Wright, ${ }^{1,2} \mathrm{~T}$ Bruns, ${ }^{1} \mathrm{~K}-\mathrm{K}$ Li, ${ }^{1} \mathrm{H}$ Shah, ${ }^{1} \mathrm{D}$ Adams, ${ }^{3} \mathrm{~J}$ Ferguson, ${ }^{1} \mathrm{G}$ Hirschfield. ${ }^{1}$ NIHR Biomedical Research Unit and Centre for Liver Research, University of Birmingham, Birmingham, UK; ${ }^{2}$ Department of Internal Medicine IV, Jena University Hospital, Friedrich Schiller University Jena, Jena, Germany; ${ }^{3}$ Liver Unit, University Hospitals Birmingham, Queen Elizabeth Hospital, Birmingham, UK

\subsection{6/gutjpl-2014-307263.199}

Introduction Autoimmune sclerosing cholangitis is the paediatric term applied to children presenting with features of autoimmune hepatitis and sclerosing cholangitis. We hypothesised that if this inflammatory phenotype was a continuum, young adults with primary sclerosing cholangitis (PSC) would also have a more inflammatory presentation.

Methods We undertook a retrospective case-note review of our patients with an established diagnosis of PSC presenting between 2003-2013 ( $\mathrm{n}=116)$. Clinical characteristics and laboratory 